\title{
The sigma-1 receptor as key common factor in cocaine and food-seeking behaviors
}

\author{
David Aguinaga 1,2, Mireia Casanovas ${ }^{1,2}$, Rafael Rivas-Santisteban ${ }^{1,2}$, Irene Reyes-Resina ${ }^{1,2, \dagger}$, Gemma Navarro ${ }^{2,3}$ and \\ Rafael Franco ${ }^{1,2}$
}

1Department of Biochemistry and Molecular Biomedicine, School of Biology, Universitat de Barcelona, Barcelona, Spain 2Centro de Investigación en Red, Enfermedades Neurodegenerativas, CiberNed, Instituto de Salud Carlos III, Madrid, Spain

3Department of Biochemistry and Physiology, School of Pharmacy and Food Sciences, Universitat de Barcelona, Barcelona, Spain

Correspondence should be addressed to R Franco or G Navarro: rfranco123@gmail.com or dimartts@hotmail.com

${ }^{\dagger}($ I Reyes-Resina is now at Research Group Neuroplasticity, Leibniz Institute for Neurobiology, Magdeburg, Germany)

\begin{abstract}
Addiction and eating disorders involve brain reward circuits. Binge eating predisposes to addictive behavior, while the cessation of exposure to drugs of abuse leads to reward activities, including intake of tasty foods. Cocaine use is associated with a decrease in food intake, with reversal after drug use is discontinued. Exciting new findings show that receptors for the 'hunger' hormone, ghrelin, directly interact with the sigma-1 receptor $\left(\sigma_{1} R\right)$, which is a target of cocaine. $\sigma_{1}$ Rs are key players in regulating dopaminergic neurotransmission and ghrelin-mediated actions. This review focuses on the $\sigma_{1}$ receptor as a general neuroendocrine regulator by directly interacting with neuronal G-proteincoupled receptors. This review also covers the early mechanisms by which cocaine binding to $\sigma_{1}$ blocks the food-seeking behavior triggered by ghrelin. Those findings appear as fundamental to understand common mechanisms in drug addiction and eating disorders.
\end{abstract}

\author{
Key Words \\ - Dopamine receptors \\ - Ghrelin receptors \\ - Orexin receptors \\ - MAP kinase \\ - Receptor heteromers \\ - Drug addiction \\ - Reward circuits of the CNS \\ - Calcium signaling \\ - cAMP/PKA signaling
}

Journal of Molecular Endocrinology (2019) 63, R81-R92

\section{Introduction}

Food-seeking behavior involve peripheral and central players, ghrelin being one of the most relevant. Ghrelin is synthesized in the stomach but its endocrine action is exerted, among others, in heart, gastrointestinal (GI) tract, pancreas and central nervous system (CNS) (Fig. 1). Ghrelin, the 'hunger' hormone, acts via a specific receptor, GHS- $\mathrm{R}_{1 \mathrm{a}}$, which belongs to the superfamily of G-protein-coupled receptors (GPCRs). Dopamine, one of the main neurotransmitters in the brain, is a key player in the circuits in which neuronal GHS- $\mathrm{R}_{1 \mathrm{a}}$ expression occurs. Also, dopamine is central to the actions of a variety of drugs of abuse, in particular cocaine. South American tribes used cocaine for endurance enhancement and appetite suppression, indicating a long history of use without fully understanding the mechanisms of action. Recent results show that one atypical receptor of unknown physiological function, the sigma- 1 receptor $\left(\sigma_{1} R\right)$, is a key piece of the puzzle showing interrelationships between cocaine and foodseeking behaviors. First, this review covers the role of $\sigma_{1} \mathrm{R}$ in cocaine addiction via GPCR-mediated regulation of dopaminergic transmission. The second part covers recent data showing how sigma receptors regulate ghrelinergic signaling. Finally, the review presents the novel and relevant evidence linking cocaine-mediated suppression of appetite with both cocaine binding to $\sigma_{1} \mathrm{R}$ and subsequent regulation of the functionality of dopamine and ghrelin GPCRs. 


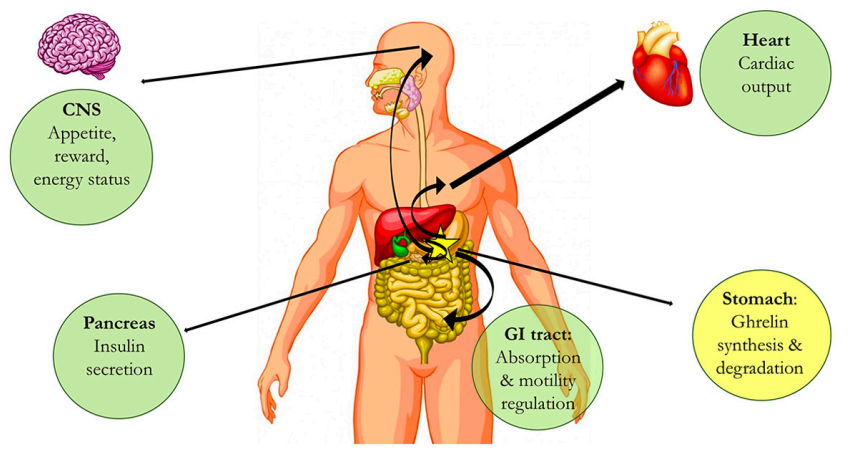

Figure 1

Endocrine actions of ghrelin in different body organs. Ghrelin is produced in the stomach (yellow) and exerts actions in different parts of the mammalian body. Examples of organs and actions are in green circles.

Apart from acting via inhibition of dopamine transporters in neurons, cocaine is able to interact with sigma- 1 and sigma- 2 receptors. The physiological role of the two receptors is unknown and, also, they are structurally unrelated despite sharing the same name (sigma). This review focuses on $\sigma_{1} \mathrm{R}$ as a mediator of the anorexigenic effect of cocaine. The receptor, whose function remains a mystery, displays interesting features such as its capacity to (i) bind cocaine at physiologically relevant concentrations and (ii) modulate GPCR function. Early evidence indicated a blockade of stimulant effect of cocaine by targeting $\sigma_{1} \mathrm{R}$ (Menkel et al. 1991). It should be noted that treatment with synthetic drugs acting on $\sigma_{2}$ receptors decreases some of cocaine-induced effects (Matsumoto et al. 2007) and that antagonist of the receptor counteract induced locomotor stimulation in cocaine-administered mice (Lever et al. 2014). However, the research on $\sigma_{2}$ receptor is still too preliminary to allow establishing a solid link between the receptor and addiction mechanisms. One of the novel aspects in the review, which is based on recent results, is the advance in understanding how cocaine consumption reduces food-seeking behavior. Apparently, this is due to direct interactions with the receptor for the hunger hormone, ghrelin.

The most striking and accepted effect of cocaine in brain is an increase in inter- and extra-synaptic dopamine concentration that leads to marked activation of dopamine receptors (Fig. 2). These and many other neuronal receptors belonging to the family of GPCRs use cAMP as second messenger. Information taken from the British Society guide for pharmacology shows sigma receptors' atypical properties: they do not use either cAMP or any other second messenger as calcium ions or inositol-3-phosphate. As $\sigma_{1} \mathrm{R}$ are not coupled to any known signal transduction machinery, the guide indicates that 'there is only a modest pharmacological overlap and no structural convergence with the GPCRs' (http://www. guidetopharmacology.org/GRAC/FamilyDisplayForward? familyId=785). On the other hand, structurally different

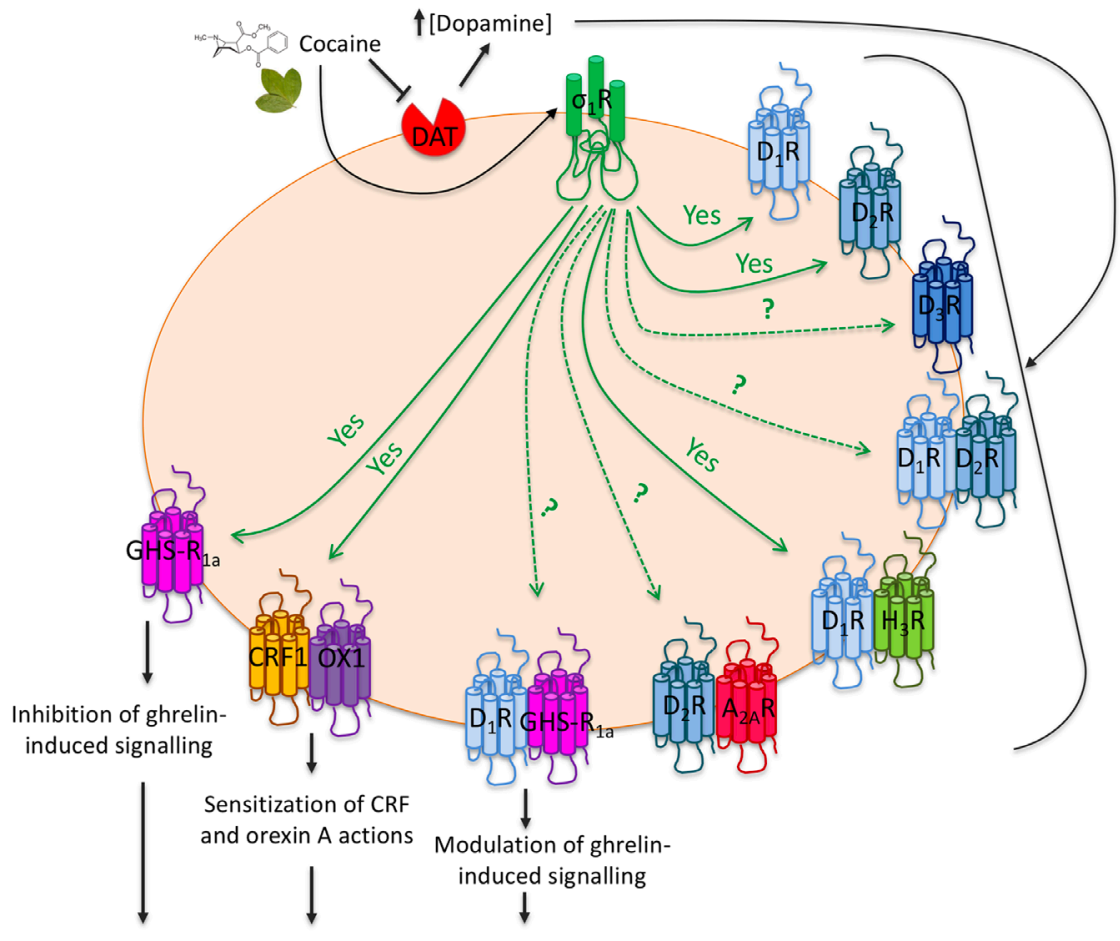

Direct action on apetite and food-seeking behaviour

\section{Figure 2}

Schema of $\sigma_{1}$ receptor-mediated actions related with food intake and mediated by neuronal GPCRs. Cocaine increases extraneuronal dopamine concentration and activates $\sigma_{1}$ receptors. Interactions of $\sigma_{1}$ and dopamine receptors or dopamine receptor-containing heteromers indirectly regulate food-seeking behavior. Interactions with ghrelin, orexin or CRF receptors directly regulate food consumption habits. Arrows originating at $\sigma_{1}$ receptors indicate proven (continuous 'yes') or suspected/unproven interactions. Dopamine receptors types appear as $D_{1} R, D_{2} R$, or $D_{3} R$. Adenosine $A_{2 A}$ receptors appear as $A_{2 A} R$. Histamine $H_{3}$ receptors appear as $H_{3} R$. Other abbreviations are for ghrelin (GHS- $\mathrm{R}_{1 \mathrm{a}}$ ), CRF (CRF1) and orexin (OX1) receptors. 
compounds may bind to $\sigma_{1} \mathrm{R}$ receptors at topologically intracellular sites. In fact, the binding of a drug seemingly acting on opioid receptors suggested that $\sigma_{1} \mathrm{R}$ receptors belonged to the opioid receptor family. The uniqueness of the receptor was first confirmed by the lack of effect of opioid receptor antagonists and, secondly, by cloning and discovering that it was not a GPCR. Solving of 3D structure (see details below) has confirmed some of the assumptions about these receptors and has provided brand new information related to atypical membrane insertion and oligomeric (trimeric) structure.

\section{Evidence for a relevant role of $\sigma_{1} R$ on cocaine addiction}

SKF-10,047 displays psychomimetic activity while it does not selectively bind to $\mu$ - or k-opioid receptor. Although it was firstly assumed that the compound could bind to a novel opioid receptor (Martin et al. 1976), its effect was not blocked by nonselective opioid receptor antagonists (Vaupel 1983). The compound in fact binds to $\sigma_{1} R$ whose cloning showed that it does not have the seven transmembrane domains of all GPCRs (Hanner et al. 1996). While waiting for more precise details on its physiological role, the $\sigma_{1} \mathrm{R}$ is considered a pluripotent modulator able to interact with different specific proteins (e.g. binding immunoglobulin protein (BiP)) and/or components of signal transduction machineries (Su et al. 2016). $\sigma_{1} \mathrm{R}$ may interact with receptors for a variety of hormones/ neurotransmitters and modulate cell surface expression and/or function. Research on this protein is gaining momentum due to its potential as a target to combat neuropathic pain (Mei \& Pasternak 2002, Corbera et al. 2006, Sun et al. 2016). Agonistic activity in the case of $\sigma_{1} R$ may be indirectly measured by subcellular translocation, establishment of protein-protein interactions or regulation of ion channel activity (Wu \& Bowen 2008, Kim et al. 2010, Navarro et al. 2010, Su et al. 2010). Indirect evidence also shows the involvement of $\sigma_{1} \mathrm{R}$ in neurological disorders such as depression (Su et al. 2010). Also interesting is the correlation between a mutation in the receptor and debut and progression of juvenile lateral amyotrophic sclerosis (Al-Saif et al. 2011, Mavlyutov et al. 2013). More recently, a biophysical approach assessing homomerization of $\sigma_{1} R$ and heteromerization of $\sigma_{1} R$ with $\mathrm{BiP}$ has allowed distinguishing molecules with differential potential on stabilizing multimerization of the receptor and/or facilitating the $\sigma_{1} \mathrm{R} / \mathrm{BiP}$ interaction (Yano et al. 2018). Despite the ambiguity of 'agonist/antagonist' words in the case of this 'receptor', the authors show that haloperidol and (+)-pentazocine have opposite effects, thus paving the way to effectively test or select molecules with 'agonistic' versus opposite ('antagonistic') actions.

Solving the 3D structure (Schmidt et al. 2016) provided a further unexpected finding. $\sigma_{1} \mathrm{R}$ does not have, as previously hypothesized, two transmembrane domains and extracellular C- and N-terminal domains, but an extracellular N-terminal end, a transmembrane $\alpha$-helical domain and a C-terminal tail having a cupin-like $\beta$-barrel with a buried ligand-binding site. Adjacent molecules show a homo-oligomeric arrangement consisting of three closely interacting $\sigma_{1} \mathrm{R}$ protomers. Despite homology (relatively poor) with a fungal sterol isomerase (Cobos et al. 2008), no catalytic activity has been yet allocated to $\sigma_{1} \mathrm{R}$.

$\sigma_{1} \mathrm{R}$ may interact with receptors for a variety of hormones/neurotransmitters (see below and Fig. 2), thus raising the hypothesis that the receptor could regulate the expression and/or the function of cell-surface receptors. Kruse recently reviewed the intriguing features of this protein that shows no structural resemblance with any other membrane receptor, that has an occluded ligand-binding site and that resembles a yeast enzyme, yeast sterol isomerase (Kruse 2017). Remarkably, while the physiological function remains elusive and the endogenous ligand is yet to be discovered, cocaine binds to $\sigma_{1} \mathrm{R}$ (Skuza 1999, Shull 2002, Lever et al. 2016). The design of drugs impeding the interaction of cocaine with $\sigma_{1} \mathrm{R}$ was proposed to reduce drug-seeking behavior (Matsumoto et al. 2001a). It is now well established that $\sigma_{1} \mathrm{R}$-mediated cocaine actions in the CNS are dependent on molecular interactions with dopamine and other GPCRs.

\section{Cocaine drives many of its effects via activation of $\sigma_{1} R$}

Apart from the well-known fact that cocaine markedly enhances the extracellular levels of dopamine in several regions of the CNS, the mechanism underlying drug addiction seems to be mediated by the $\sigma_{1} \mathrm{R}$.

To our knowledge there are few reports addressing cocaine binding to $\sigma_{1} R$. It is however relevant that the interaction of cocaine with $\sigma_{1} \mathrm{R}$ was suspected several years ago (see; Hayashi \& Su 2007 for review). Pioneering studies on cocaine binding to $\sigma_{1} \mathrm{R}$ were performed in 2001 (Matsumoto et al. 2001b). Competition assays in radioligand-binding studies showed that $K_{\mathrm{i}}$ of cocaine was 2.3 in mouse and $2.9 \mu \mathrm{M}$ in rat brain. Values were similar in mice brain membranes (Lever et al. 2016) thus confirming that at 'physiological' concentrations occurring after 
cocaine exposure the drug binds to $\sigma_{1}$ Rs. Based on these results, Matsumoto proposed that $\sigma_{1}$ Rs were targets to combat cocaine addiction (Matsumoto et al. 2003). More recently, a detailed study (Lever et al. 2016) showed that cocaine administration to mice reduces the binding of a radiolabeled ligand and it does so in a similar proportion in the 20 different brain regions analyzed by quantitative autoradiography. Average reduction of specific binding after i.p. administration of $100 \mu \mathrm{mol} / \mathrm{kg}$ cocaine was $54 \%$. It should be noted that the $\sigma_{1} \mathrm{R}$ is expressed in all brain regions in a narrow range of $2-4 \mathrm{fmol} / \mathrm{mg}$ tissue.

A significant advance in addiction research has been provided by demonstrating a link between $\sigma_{1} R$ and the MAP kinase pathway. The receptor, by itself or upon cocaine binding, cannot convey signals that directly impact on such key signaling pathway. The most reasonable assumption is that cocaine binding to $\sigma_{1} R$ produces conformational changes in cell-surface GPCRs that are in direct contact with $\sigma_{1} \mathrm{R}$. This possibility not only affects signaling but also the overall biology of those GPCRs that have a crucial role in drug addiction and control of food intake.

The first in-depth review on the role of $\sigma_{1} \mathrm{R}$ in the many different sides of cocaine addiction appeared in 2002 (Romieu et al. 2002). The already existing data made authors state ' $\sigma_{1} R$ is not only necessary for acquisition of the cocaine-induced conditioned place preference, but that it is also implicated in its expression, confirming that activation of the $\sigma_{1} \mathrm{R}$ is induced during cocaine's early effects'. A more recent review, that summarizes the main properties of $\sigma_{1} R$, emphasizes its role as a chaperone (see; Katz et al. 2017 and references therein). The review also presented the evidence of receptor involvement in three specific aspects of drug addiction, namely selfadministration, discrimination and place conditioning. We will here focus on the molecular mechanisms that triggered by cocaine binding to $\sigma_{1} \mathrm{R}$ are mediated by other proteins. It was proposed that there is a 'concomitant targeting of both dopaminergic pathways and $\sigma \mathrm{R}$ proteins' (Katz et al. 2017). However, recent evidence is more consistent with a more direct effect of cocaine on dopaminergic transmission and on other signaling systems operating in neurons of reward circuits. It is quite noteworthy that in the review by Romeu the authors intuitively noticed this possibility and stated: 'The $\sigma_{1} \mathrm{R}$ is activated consequently to dopamine reuptake blockade and is not sufficient to induce conditioned place preference (CPP) by itself. The mechanism of the $\sigma_{1} \mathrm{R}$ involvement in CPP and the selectivity toward the CPP-inducing drug remains however to be determined'
(Romieu et al. 2002). In fact, data obtained in the last decade suggest new possibilities that have increased the knowledge of underlying mechanisms. In what concerns dopaminergic signaling, cocaine binding to $\sigma_{1} \mathrm{R}$ produces a direct effect on dopaminergic transmission. This is possible because the $\sigma_{1} \mathrm{R}$ directly interacts with dopamine receptors (Fig. 2) and, accordingly, cocaine is binding to and affecting the structure and function of $\sigma_{1} /$ dopamine receptor complexes.

\section{Lessons from drugs behaving as $\sigma_{1} R$ ligands}

Pioneering studies aimed at understanding the role of $\sigma_{1} \mathrm{R}$ in cocaine effects, showed a synthetic ligand, NPC 16377, was protective against the behavioral effects of cocaine. NPC 16377 did not show any noticeable side effect while its efficacy was quite marked; for instance, it totally prevented the development of cocaine sensitization and significantly reduced diazepam-sensitive cocaine convulsions. Its effects were quite selective; it was not a NMDA receptor ligand and was not efficacious against discriminative stimuli triggered by other drugs (Witkin et al. 1993). Similar results were obtained using compounds with different chemical structures that reduced cocaineinduced hyperlocomotion and convulsions being able to bind to $\sigma_{1} \mathrm{R}$ but not to other receptors (McCracken et al. 1999, Shull 2002).

Skuza tested different sigma receptor ligands, rimcazole and panamesine among others, on cocaineinduced locomotor activity in rats and convulsions (Skuza 1999). Whereas panamesine reduced the two actions of the drug of abuse, rimcazole increased the total time of cocaine-evoked convulsions and locomotor activity. The author concluded: ' $\sigma_{2} \mathrm{R}$ subtype is involved in psychomotor stimulant effects of cocaine while $\sigma_{1} \mathrm{R}$ subtype participates in the cocaine-induced convulsions'. Also, Romieu and colleagues showed that two novel $\sigma_{1} \mathrm{R}$ ligands, BD1063 and BD1008, significantly increased the $\mathrm{ED}_{50}$ for the locomotor effects of cocaine attributing the effects to dopamine transporter inhibition (Romieu et al. 2000). However, testing different concentrations of analogs of rimcazole for their ability to bind to the two main targets of cocaine, dopamine transporters and $\sigma_{1} \mathrm{R}$, (Matsumoto et al. 2001a and 2001b) were successful in showing that drugs protective against convulsionproducing concentrations of cocaine were not acting via dopamine transporter inhibition but via binding to $\sigma 1 \mathrm{R}$. In a follow-up study six analogs of BD1008 were tested against a variety of targets showing significant affinity for $\sigma_{1} R$, moderate for $\sigma_{2} R$ and low or very low affinity for 
dopamine transporters and for dopamine, opioid, NMDA and 5-hydroxytryptamine receptors (Matsumoto et al. 2004). The involvement of $\sigma_{1} \mathrm{R}$ was further confirmed using an antisense oligodeoxynucleotide approach, which was efficacious in reducing the behavioral effects of cocaine (Matsumoto et al. 2001a and 2001b). Taking into account all the evidence, antagonists of $\sigma_{1} \mathrm{R}$ were proposed as therapeutic agents to fight against cocaine addiction (Matsumoto et al. 2001c, 2003, Maurice \& Romieu 2004). It should be however noted that $\sigma_{1} \mathrm{R}$-based therapies may not work on acute symptoms and may be better suited to address drug sensitization. Indeed, a common phenomenon displayed by all ligands tested is the reduction in psychostimulant-induced sensitization, not only to cocaine but also to methamphetamine (Ujike et al. 1996).

$\sigma_{1} \mathrm{R}$ impacts on signaling pathways originating at GPCRs and also on the function of ion channels; overall, these functional interactions shape the behavioral and neuroanatomical alterations leading to cocaine addiction (Kourrich et al. 2013). One relevant aspect to consider is how $\sigma_{1} \mathrm{R}$ may affect dopaminergic signaling. As an example, the $\mathrm{D}_{1}$ receptor-mediated signaling and dopamine-induced inositol 1,4,5-trisphosphate production have been studied in dissociated neurons of the nucleus accumbens (NAc). The main finding was that the calcium mobilization produced by administration of inositol 1,4,5-trisphosphate was enhanced by cocaine in a $\sigma_{1} \mathrm{R}$-dependent fashion. Not only cocaine increases the effects of agonists on cAMP levels but it also alters the kinetics of the MAP kinase pathway engagement. Remarkably, $\mathrm{D}_{1}$ and $\sigma_{1}$ receptors do interact and the cocaine effect on dopaminergic signaling was dependent on $\sigma_{1} R$, a fact that was confirmed by using $\sigma_{1} \mathrm{R}$ KO mice (Navarro et al. 2010).

\section{Cocaine, dopamine, dopamine receptors, and dopamine heteroreceptor complexes}

Dopamine is one of the main neurotransmitters in the brain, and its actions, mediated by dopamine receptors, are relevant for motor control and are important in the reward circuits targeted by addictive drugs. Pioneering electrophysiological studies by Uchimura and North showed that intracellular recordings in NAc neurons triggered by 5 -hydroxytryptamine or by dopamine were affected by cocaine (Uchimura \& North 1990). The drug at doses in the $1-30 \mu \mathrm{M}$ range affects dopamine $\mathrm{D}_{1}$-receptor-mediated hyperpolarization and $\mathrm{D}_{2}$-receptormediated depolarization. Cocaine was more effective, that is, less doses were required to alter the actions of 5-hydroxytryptamine.

Nowadays, GPCR-containing heteroreceptor complexes are considered as real functional units. In cocaine addiction, the engagement of $\sigma_{1} \mathrm{R}$ by cocaine and the interaction of these receptors with GPCRs has led to investigate how heteromers may contribute to the behavior and motor effects of the drug. As an example, complexes formed by dopamine $\mathrm{D}_{1}$ and histamine $\mathrm{H}_{3}$ receptors display particular properties: the heteromer is needed for signaling to the MAP kinase pathway (Ferrada et al. 2009). Again, cocaine alters heteromer function via the $\sigma_{1} \mathrm{R}$ (Moreno et al. 2014). These results probably reflect the occurrence of a macromolecular complex constituted by $\mathrm{H}_{3}, \mathrm{D}_{1}$ and $\sigma_{1}$ receptors, whose structure and function becomes altered in the presence of cocaine. This interpretation is supported by the finding that $\sigma_{1} \mathrm{R}$ antagonists restore the homeostatic interplay between $\mathrm{H}_{3}$ and $\mathrm{D}_{1}$ receptors and, therefore, supports the potential of $\sigma_{1} \mathrm{R}$ antagonists to combat drug addiction.

Cocaine affects signaling of other dopamine receptorcontaining heteromers also in a $\sigma_{1}$ R-dependent fashion (Fig. 2). Adenosine $A_{2 A}$ and dopamine $D_{2}$ receptor heteromers were among the first-identified GPCR heteromers (Hillion et al. 2002). $\mathrm{A}_{2 \mathrm{~A}} \mathrm{R}-\mathrm{D}_{2} \mathrm{R}$ heteromers play a relevant role in the striatum and are the target for therapeutic approaches addressed to combat Parkinson's disease; the homeostatic mechanism consists of $\mathrm{A}_{2 \mathrm{~A}} \mathrm{R}$ mediated brake of dopamine actions on $\mathrm{D}_{2}$ receptors. On the one hand, energy transfer studies showed that cocaine altered the structure of adenosine receptor homomers and of adenosine/dopamine receptor heteromers. On the other hand, the drug affected some but not all of the signaling pathways engaged by activation of $\mathrm{D}_{2}$ receptors (Marcellino et al. 2010). Taking into account data on the molecular mechanisms of cocaine actions, Borroto-Escuela et al. (2016b) hypothesized that the drug is significantly altering the allosteric interactions occurring in homo- and heteroreceptor complexes, especially in those containing dopamine receptors. Taking also into account the differential distribution of receptors in different brain regions and the changes in receptor expression after cocaine exposure, the authors suggested that (i) anti-cocaine actions of $\mathrm{A}_{2 \mathrm{~A}}$ agonists do not depend on heteromerization of $\mathrm{A}_{2 \mathrm{~A}} \mathrm{R}$ with $\mathrm{D}_{2}$ receptors and (ii) cocaine self-administration courses with a loss in dorsal striatopallidal GABAergic neurons of the brake on $D_{2}$ receptor signaling within the $A_{2 A} R-D_{2} R$ receptor heteroreceptor complex. 
Cocaine administration to non-human primates results in brain concentration peaks appearing as soon as $5 \mathrm{~min}$ to go back to basal at $30 \mathrm{~min}$ (Bradberry et al. 2000). A key region for addiction behavior establishment is the NAc. A novel technique of heteromer detection shows that cocaine self-administration increases the expression of $\mathrm{A}_{2 \mathrm{~A}} \mathrm{R} / \mathrm{D}_{2} \mathrm{R}$ and $\mathrm{D}_{2} \mathrm{R} / \sigma_{1} \mathrm{R}$ complexes in the shell of the NAc, whereas it decreases the expression of those constituted by $\mathrm{D}_{2} \mathrm{R}$ and $\sigma_{1} \mathrm{R}$ in the dorsal striatum (Borroto-Escuela et al. 2017). Thus, self-administration likely increases in a regional-selective way the expression of receptors that may establish direct interactions and display particular signaling pathways. It should be noted that $\sigma_{1} \mathrm{R}$ may form heteromers with $\mathrm{D}_{2}$ receptors but not with other $\mathrm{D}_{2}$-like receptors such as $\mathrm{D}_{3}$ or $\mathrm{D}_{4}$ receptors. The drug inhibits dopaminergic signaling in the striatum of wild-type mice but not in the striatum of $\sigma_{1} \mathrm{R}$ KO mice. As commented below, altering $\mathrm{D}_{1}$-receptor-mediated signaling modifies the $\mathrm{D}_{1}-\mathrm{D}_{2}$ balance required for proper motor control (Navarro et al. 2013). $\sigma_{1}$ R-mediated dysbalance on striatal dopaminergic signaling is probably one of the main factors underlying locomotor actions of cocaine.

A small but significant percentage of neurons in the NAc express $\mathrm{D}_{1}$ and $\mathrm{D}_{2}$ dopamine receptors. There is dispute on the possibility that $\mathrm{D}_{1}$ and $\mathrm{D}_{2}$ may form heteroreceptor complexes in motor control brain areas (Lee et al. 2004, Rashid et al. 2007, Perreault et al. 2010, George et al. 2014, Frederick et al. 2015, Rico et al. 2016). The most likely hypothesis is that $10-20 \%$ of neurons in the NAc express both receptors and that they establish heteroreceptor complexes shifting dopaminergic transmission from cAMP- to $\mathrm{Ca}^{2+}$-dependent signaling (Hasbi et al. 2009). As the increase of dopamine in this nucleus is fundamental for addiction and a significant amount of these cells express the two dopamine receptors, it is hypothesized that $\mathrm{D}_{1} / \mathrm{D}_{2}$ heteroreceptor complexes are important for the establishment of cocaine-seeking behavior. In line with this hypothesis, recent studies show that disruption of the heteromer has profound consequences in animals treated with cocaine. Intracerebroventricular administration of disrupting peptides, induces, sustains, accelerates and exacerbates the incentive motivational and locomotor activating effects of cocaine in a self-administration paradigm. The blocking peptides were also able to increase $\triangle$ FosB expression in the NAc. These findings suggest a model for tonic inhibition of basal and cocaine-induced reward (Perreault et al. 2016). Future experiments should address the question of whether $\sigma_{1} \mathrm{R}$ may interact with $\mathrm{D}_{1} / \mathrm{D}_{2}$ heteroreceptors and mediate cocaine actions in neurons expressing the two receptors.

\section{Cocaine alters mitogen-activated protein kinase (MAP) pathway via GPCRs}

One of the common factors in drug addiction is the involvement of the MAP kinase pathway. Many drugs of abuse and also natural compounds with psychoactive effects have an impact on the pathway. Structurally different drugs such as tetrahydrocannabinol (THC) or cocaine increase the phosphorylation of extracellular signal-regulated kinases (ERKs) in different brain regions thus fitting with impaired CPP upon pharmacological blockade of the pathway. Furthermore, activation of the MAP kinase pathway contributes to the plastic changes induced by drugs of abuse (see; Valjent et al. 2004 and references therein). Activation of the MAP kinase pathway is needed for establishing an association between drug consumption and CPP (Valjent et al. 2006, Du et al. 2017). Of the two predominant ERK isoforms, ERK2 seems more directly involved in remodeling produced by repeated exposure to cocaine. This conclusion arises from data in ERK1 KO mice, which display a facilitation of acquisition of cocaine CPP and of locomotor sensitization (Ferguson et al. 2006). Also interesting is the finding that dopamine $\mathrm{D}_{1}$ receptor mediates cocaine-induced longterm plasticity in the NAc (Zhang et al. 2017). On the one hand, dopamine supersensitivity, which is subsequent to cocaine consumption, alters the homeostasis of the pathway. Although the temporal course of cocaineinduced increase of dopamine occurs mainly in ventral striatum (Kalivas 1993, Kalivas \& Duffy 1993), it affects other brain regions in virtue of the volume transmission mechanism defined by Agnati et al. (1986). On the other hand, whereas THC or caffeine act by direct binding to GPCRs, a direct effect of cocaine on those receptors is unlikely. Interestingly enough, cocaine binding to $\sigma_{1} \mathrm{R}$ does impact on the signal transduction mechanisms that originate at GPCRs and regulate the MAP kinase and mTOR pathways (see; Franco et al. 2017 and references therein). In the amygdala, which is also affected in cocaine addiction, acute and chronic drug administration produced different patterns of immediate early gene expression that correlated with ERK phosphorylation (Radwanska et al. 2005). In summary, the MAP kinase pathway arises as a key mediator of the central actions produced in response to cocaine administration.

\section{Orexin and ghrelin receptors}

Orexin/hypocretin physiology and orexin receptor pharmacology data suggest that orexigenic receptors have 
therapeutic potential in food disorders and drug addiction (Kukkonen \& Leonard 2014, Leonard \& Kukkonen 2014). Such hypothesis is partly based on the fact that orexin G-protein-coupled receptor pharmacology is multifaceted, ranging from activation of $G$ proteins to ion flux regulation.

Cocaine-seeking behavior involves the ventral tegmental area and several mediators such as orexin-A and corticotropin-releasing factor (CRF). Again, receptors related with cocaine effects have the possibility of forming heteromers whose function is affected by the drug. As a relevant example, CRF1 (CRF1R) interacts with orexin OX1 receptors, and the interaction results in a negative crosstalk between orexin-A and CRF; these endogenous transmitters regulate dendritic dopamine release in the ventral tegmental area. $\sigma_{1} \mathrm{R}$ also interacts with those heteroreceptor complexes, and cocaine binding to $\sigma_{1} \mathrm{R}$ sensitizes cells to excitatory effects of CRF and orexin-A; the mechanism consists of a crosstalk within protomers in CRF1-OX1 receptor heteromers (Navarro et al. 2015). These results reflect an interplay between addiction, stress and, importantly, control of food intake by orexigenic factors (Fig. 2).

Ghrelin is a peptide hormone that controls food intake and energy homeostasis (Fig. 1). Its action is mediated by specific receptors that have received a variety of denominations such as growth hormone-releasing peptide or growth hormone secretagogue receptor. Ghrelin receptors belong to the GPCR superfamily and only one type has been identified. The full-length 388 amino acid long human ghrelin receptor containing seven transmembrane domains is known as GHS- $\mathrm{R}_{1 \mathrm{a}}$, to differentiate it from the GHS- $\mathrm{R}_{1 \mathrm{~b}}$ splice variant, which is 289 amino-acid-long and lacks the fifth and sixth transmembrane (TM) domains. These TM domains are required for coupling to heterotrimeric $G$ proteins and, therefore, ghrelin cannot signal via GHS- $\mathrm{R}_{1 \mathrm{~b}}$ receptors (Mary et al. 2013). The truncated variant seems to serve as modulator of GHS- $\mathrm{R}_{1 \mathrm{a}}$ surface expression and signaling. In fact, GHS- $\mathrm{R}_{1 \mathrm{~b}}$ is expressed in the same cells than GHS- $\mathrm{R}_{1 \mathrm{a}}$ and both receptors interact to form signaling units (Mary et al. 2013). It has been reported that GHS- $\mathrm{R}_{1 \mathrm{~b}}$ negatively influences ghrelin action by reducing surface expression of functional G-protein-coupled ghrelin receptors (Chow et al. 2012) and by allosteric interactions that reduce the efficacy of the hormone (Mary et al. 2013).

In a detailed review Schellekens et al. (2013a) nicely summarize how activation of specific receptors in the brain shapes the many actions of the so-called hunger hormone. The link between ghrelin and dopaminergic transmission in reward circuits is highlighted: 'The ghrelin signaling system has recently been suggested to play a key role at the interface of homeostatic control of appetite and the hedonic aspects of food intake, as a critical role for ghrelin in dopaminergic mesolimbic circuits involved in reward signaling has emerged'. They also point out that ghrelin receptors may establish interactions with other proteins (Schellekens et al. 2013a,b); in fact, ghrelin receptors establish direct protein-protein interactions with a variety of GPCRs: dopamine, melanocortin, prostanoid, serotonin, somatostatin and neurotensin receptors (see; Borroto-Escuela et al. 2014 and references therein; see www.gpcr-hetnet.com). In a detailed study in which complexes formed by GHS- $\mathrm{R}_{1 \mathrm{a}}-$ GHS- $\mathrm{R}_{1 \mathrm{~b}}$ and dopamine $\mathrm{D}_{1}$ receptors were detected, ghrelin receptor signaling was different in hippocampus versus striatum. In the latter, $\mathrm{D}_{1}$ receptors were involved in GHS- $\mathrm{R}_{1 \mathrm{a}}$-Gs/olf coupling. Thus, the dopamine receptor may switch from $G_{i / o}$ to $G_{s / o l f}$ coupling but only if GHS- $\mathrm{R}_{1 \mathrm{~b}}$ is also expressed (Navarro et al. 2016). It then appears that anything affecting $D_{1}$ receptor-mediated signaling may in turn affect ghrelin actions.

\section{Links between drug addiction and anorexic behavior}

Used today as recreational drug, cocaine was first consumed by humans in the form of Coca leaves. Indeed, indigenous peoples of South America knew that chewing coca leaves was key for keeping their life style. Coca served to cope with the harsh living conditions, for instance when people had to travel long distances and cross Andean mountains with little food. Despite such ancient knowledge, that is, the appetite suppressant action of cocaine, the molecular basis of hunger dissipation by the drug has remained elusive. Interestingly, years ago it was shown that antagonists of $\sigma_{1} \mathrm{R}$ blocked compulsive eating behavior in rats (Cottone et al. 2012). These early results fit nicely with those of a recent report that has provided insight into the underlying molecular mechanisms.

Addiction and eating disorders (i.e. binge eating, anorexia, bulimia) share a central control that involves reward circuits in the brain. This leads to bidirectional influences: on one hand, previous history of binge eating predisposes to the addictive behavior, whereas the cessation of exposure to drugs of abuse leads to rewardproviding activities, including the intake of palatable foods. This fact reflects a vicious circle in which the weight gain that follows cocaine abstinence secondarily causes a significant distress which can make a patient 
more prone to relapses. Many uncertainties remain about the biological substrate of these changes, particularly at the level of signaling systems involved. Thus, establishing the molecular mechanisms of such complex interactions is of immense public health relevance.

Exciting new findings substantiate the concept that receptors for the 'hunger' hormone, ghrelin, interact with $\sigma_{1} \mathrm{R}$ in CNS neurons (Fig. 2). The results provide solid evidence of the anorexic effect of cocaine being mediated by ghrelin receptors, both compounds arising as key players in the central control of food/energy intake (Aguinaga et al. 2019). Importantly, the ghrelin $/ \sigma_{1} R$ interaction creates qualitatively new, higher-order structures, with altered signaling properties. Unraveling the mechanisms applicable in this setting may ultimately be translatable into new approaches in endocrinology and behavioral neuroscience fields. In addition, they arise as useful to address the social impact of anorexia/bulimia/bingeeating, now particularly worrisome in young populations.

\section{Cocaine affects ghrelin receptor traffic and function via $\sigma_{1} R$}

A first relevant piece of information concerning cocaine and ghrelin receptors concerns cell surface GHS-R $\mathrm{R}_{1 a}$ expression. Cocaine at a physiologically relevant dose is able to increase plasma membrane expression of $\sigma_{1} \mathrm{R}$ (Navarro et al. 2010). Molecules acting as $\sigma_{1} \mathrm{R}$ agonists do the same effect, thus confirming specificity. Remarkably, both cocaine and $\sigma_{1} \mathrm{R}$ agonists increase the colocalization of the two receptors at the cell surface. Accordingly, any drug interacting in an 'agonistic' manner with $\sigma_{1} \mathrm{R}$ is able to concomitantly affect the coexpression of the two receptors at the cell surface. Direct interactions have been

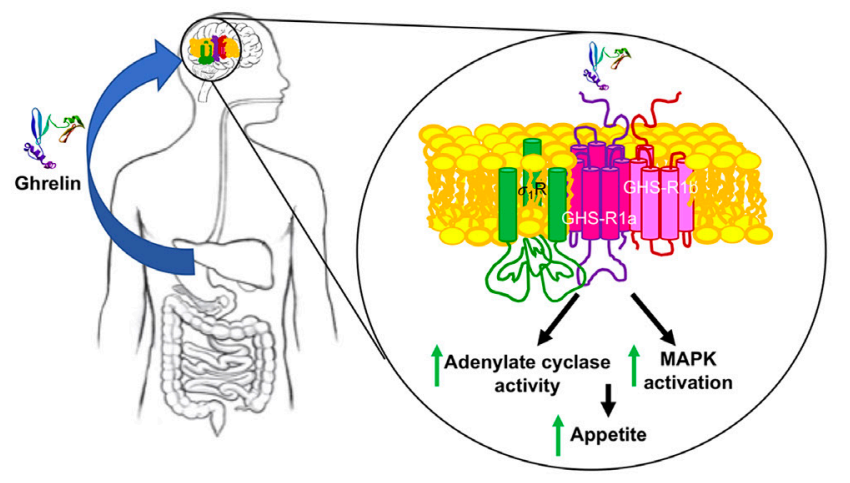

confirmed in brain sections of cocaine-treated animals and in an heterologous expression system (Aguinaga et al. 2019).

The in situ proximity ligation assay allows determining the occurrence of receptor complexes in natural sources (Borroto-Escuela et al. 2016a). The technique showed occurrence of $\sigma_{1} / \mathrm{GHS}-\mathrm{R}_{1 \mathrm{a}}$ receptor heteromeric complexes in rat brain sections. Eleven percent of cells in rat striatum displayed the fluorescent signal corresponding to those macromolecular complexes. The percentage of positive cells in animals chronically treated with the addictive drug increased to $61 \%$ and the amount of signal, measured as red clusters, also increased. The acute treatment led to a more marked increase in both the percentage of labeled cells (76\%) and the degree of labeling (3.2-fold increase). The results are consistent with both occurrence of $\sigma_{1} /$ ghrelin receptor complexes and marked upregulation of those complexes upon acute or chronic cocaine treatment. Upregulation of $\sigma_{1} / \mathrm{GHS}-\mathrm{R}_{1 \mathrm{a}}$ receptor heteromeric complexes was also obtained in primary cultures of striatal neurons treated with cocaine. These findings led to the hypothesis that cocaine binding to $\sigma_{1}$ receptors could affect the ghrelin receptor-mediated signaling. The hypothesis was confirmed in a heterologous expression system and in primary cultures of striatal neurons (Aguinaga et al. 2019).

Consistent with the coupling of ghrelin receptor to heterotrimeric Gi proteins, its activation using endogenous ghrelin in the presence of forskolin significantly decreases intracellular cAMP levels. Signaling via Gi was blocked by both agonists of $\sigma_{1} \mathrm{R}$ and by cocaine. Signal transduction in neurons expressing GHS- $\mathrm{R}_{1 \mathrm{a}}$ leads to activation of the MAP kinase pathway. This signaling, that is, ERK phosphorylation triggered by GHS- $\mathrm{R}_{1 \mathrm{a}}$ activation, was

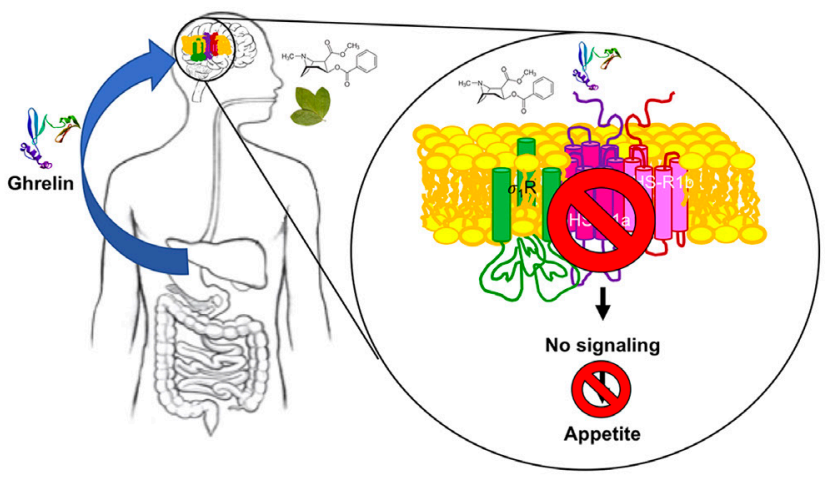

Figure 3

Mechanisms of ghrelin receptor-mediated cocaine-suppression of appetite. In the absence of cocaine, the peptide hormone ghrelin arrives to the CNS and activates GHS-R $\mathrm{R}_{1}$ in CNS neurons to engage Gi signaling and the MAPK pathway (left). In the presence of cocaine, activation of $\sigma_{1}$ produces conformational changes in GHS-R ${ }_{1 a}$ (see Aguinaga et al. 2019) that block any signaling originating at the ghrelin receptor (right). The chemical structure of cocaine is shown near the coca leaf. 
inhibited not only by ghrelin receptor antagonists but also by cocaine and $\sigma_{1} \mathrm{R}$ agonists (Fig. 3). Therefore, both G-dependent and G-independent signaling becomes compromised by cocaine binding to $\sigma_{1} \mathrm{R}$ and disappear when $\sigma_{1} \mathrm{R}$ is silenced by a siRNA methodology (Aguinaga et al. 2019).

A further relevant question was to know whether the cocaine effects were mediated by either $\sigma_{1}$ containing heteroreceptor complexes or by indirect mechanisms involving second messengers or other signaling molecules. Cocaine acting as agonist of the receptor may stabilize its trimeric structure (Gromek et al. 2014). Taking advantage of the (trimeric) 3D-structure of $\sigma_{1} \mathrm{R}$, a model was proposed for the $\sigma_{1}$ R-GHS- $\mathrm{R}_{1 \mathrm{a}}$ interaction (Schmidt et al. 2016). The model predicted that the transmembrane 1 (TM1) domain of the ghrelin receptor participates in the interaction interface, whereas TM7 does not. The issue was addressed taking advantage of interfering peptides. They have been successfully used to disrupt the structure of interactions involving GPCRs (Navarro et al. 2018). These peptides consist of receptor TM sequences followed by a short sequence of the cell-penetrating HIV transactivator of transcription (TAT) (Schwarze et al. 1999). In agreement with the model provided for $\sigma_{1}$ R-GHS- $R_{1 a}$ heteromers, the TAT-TM1 but not the TAT-TM7 blocked the effect of cocaine on GHS- $\mathrm{R}_{1 \mathrm{a}}$-mediated signaling, while the ghrelin action was still blocked by the selective ghrelin receptor antagonist. In summary, at the mechanistic level the cocaine blockade of ghrelin action occurs at a proximal level in CNS neurons by $\sigma_{1}$ Rs directly interacting with ghrelin receptors (Fig. 3).

\section{Declaration of interest}

The authors declare that there is no conflict of interest that could be perceived as prejudicing the impartiality of this review.

\section{Funding}

This work was supported by grant from Spanish Ministry of Economy and Competitiveness (MINECO) (Ref. No. BFU2015-64405-R), and by a grant from the Spanish Ministry of Science, Innovation and Universities (Ref. No. RTI2018-094204-B-I00). Both include EU FEDER funds.

\section{Author contribution statement}

I Reyes-Resina, G Navarro and R Franco contributed equally to this work.

\section{References}

Agnati LF, Fuxe K, Zoli M, Ozini I, Toffano G \& Ferraguti F 1986 A correlation analysis of the regional distribution of central enkephalin and beta-endorphin immunoreactive terminals and of opiate receptors in adult and old male rats. Evidence for the existence of two main types of communication in the central nervous system: the volume transmission and the wiring transmission. Acta Physiologica Scandinavica 128 201-207. (https://doi. org/10.1111/j.1748-1716.1986.tb07967.x)

Aguinaga D, Medrano M, Cordomí A, Jiménez-Rosés M, Angelats E, Casanovas M, Vega-Quiroga I, Canela EI, Petrovic M, Gysling K, et al. 2019 Cocaine blocks effects of hunger hormone, ghrelin, via interaction with neuronal Sigma-1 receptors. Molecular Neurobiology 56 1196-1210. (https://doi.org/10.1007/s12035-018-1140-7)

Al-Saif A, Al-Mohanna F \& Bohlega S 2011 A mutation in sigma-1 receptor causes juvenile amyotrophic lateral sclerosis. Annals of Neurology 70 913-919. (https://doi.org/10.1002/ana.22534)

Borroto-Escuela DO, Brito I, Romero-Fernandez W, Di Palma M, Oflijan J, Skieterska K, Duchou J, Van Craenenbroeck K, SuárezBoomgaard D, Rivera A, et al. 2014 The G protein-coupled receptor heterodimer network (GPCR-HetNet) and its hub components. International Journal of Molecular Sciences 15 8570-8590. (https://doi. org/10.3390/ijms15058570)

Borroto-Escuela DO, Hagman B, Woolfenden M, Pinton L, Jiménezberistain A, Ofl J, Narvaez M, Palma M Di, Feltmann K, Sartini S, et al. 2016a Receptor and ion channel detection in the brain. Neuromethods 110 109-124. (https://doi.org/10.1007/978-1-4939-3064-7)

Borroto-Escuela DO, Wydra K, Pintsuk J, Narvaez M, Corrales F, Zaniewska M, Agnati LF, Franco R, Tanganelli S, Ferraro L, et al. $2016 b$ Understanding the functional plasticity in neural networks of the basal ganglia in cocaine use disorder: a role for allosteric receptor-receptor interactions in A2A-D2 heteroreceptor complexes. Neural Plasticity 2016 4827268. (https://doi. org/10.1155/2016/4827268)

Borroto-Escuela DO, Narváez M, Wydra K, Pintsuk J, Pinton L, JimenezBeristain A, Di Palma M, Jastrzębska J, Filip M \& Fuxe K 2017 Cocaine self-administration specifically increases A2AR-D2R and D2Rsigma1R heteroreceptor complexes in the rat nucleus accumbens shell. Relevance for cocaine use disorder. Pharmacology, Biochemistry, and Behavior 155 24-31. (https://doi.org/10.1016/j.pbb.2017.03.003)

Bradberry CW, Barrett-Larimore RL, Jatlow P \& Rubino SR 2000 Impact of self-administered cocaine and cocaine cues on extracellular dopamine in mesolimbic and sensorimotor striatum in rhesus monkeys. Journal of Neuroscience 20 3874-3883. (https://doi. org/10.1523/JNEUROSCI.20-10-03874.2000)

Chow KBS, Sun J, Chu KM, Tai Cheung W, Cheng CHK \& Wise H 2012 The truncated ghrelin receptor polypeptide (GHS-R1b) is localized in the endoplasmic reticulum where it forms heterodimers with ghrelin receptors (GHS-R1a) to attenuate their cell surface expression. Molecular and Cellular Endocrinology 348 247-254. (https://doi. org/10.1016/j.mce.2011.08.034)

Cobos E, Entrena J, Nieto F, Cendan C \& Pozo E 2008 Pharmacology and therapeutic potential of sigma1 receptor ligands. Current Neuropharmacology 6 344-366. (https://doi. org/10.2174/157015908787386113)

Corbera J, Vaño D, Martínez D, Vela JM, Zamanillo D, Dordal A, Andreu F, Hernandez E, Perez R, Escriche M, et al. 2006 A medicinalchemistry-guided approach to selective and druglike sigma 1 ligands. ChemMedChem 1 140-154. (https://doi.org/10.1002/ cmdc.200500034)

Cottone P, Wang X, Park JW, Valenza M, Blasio A, Kwak J, Iyer MR, Steardo L, Rice KC, Hayashi T, et al. 2012 Antagonism of sigma-1 receptors blocks compulsive-like eating. Neuropsychopharmacology $\mathbf{3 7}$ 2593-2604. (https://doi.org/10.1038/npp.2012.89)

Du Y, Du L, Cao J, Hölscher C, Feng Y, Su H, Wang Y \& Yun KM 2017 Levo-tetrahydropalmatine inhibits the acquisition of ketamineinduced conditioned place preference by regulating the expression of ERK and CREB phosphorylation in rats. Behavioural Brain Research 317 367-373. (https://doi.org/10.1016/j.bbr.2016.10.001) https://jme.bioscientifica.com https://doi.org/10.1530/JME-19-0138 Published by Bioscientifica Ltd. Printed in Great Britain 
Ferguson SM, Fasano S, Yang P, Brambilla R \& Robinson TE 2006 Knockout of ERK1 enhances cocaine-evoked immediate early gene expression and behavioral plasticity. Neuropsychopharmacology 31 2660-2668. (https://doi.org/10.1038/sj.npp.1301014)

Ferrada C, Moreno E, Casadó V, Bongers G, Cortés A, Mallol J, Canela EI, Leurs R, Ferré S, Lluís C, et al. 2009 Marked changes in signal transduction upon heteromerization of dopamine D1 and histamine H3 receptors. British Journal of Pharmacology 157 64-75. (https://doi.org/10.1111/j.1476-5381.2009.00152.x)

Franco R, Martínez-Pinilla E, Navarro G \& Zamarbide M 2017 Potential of GPCRs to modulate MAPK and mTOR pathways in Alzheimer's disease. Progress in Neurobiology 149-150 21-38. (https://doi. org/10.1016/j.pneurobio.2017.01.004)

Frederick AL, Yano H, Trifilieff P, Vishwasrao HD, Biezonski D, Mészáros J, Urizar E, Sibley DR, Kellendonk C, Sonntag KC, et al. 2015 Evidence against dopamine D1/D2 receptor heteromers. Molecular Psychiatry 20 1373-1385. (https://doi.org/10.1038/ mp.2014.166)

George SRSR, Kern A, Smith RGRG \& Franco R 2014 Dopamine receptor heteromeric complexes and their emerging functions. Progress in Brain Research 211 183-200. (https://doi.org/10.1016/B978-0-44463425-2.00008-8)

Gromek KA, Suchy FP, Meddaugh HR, Wrobel RL, LaPointe LM, Chu UB, Primm JG, Ruoho AE, Senes A \& Fox BG 2014 The oligomeric states of the purified sigma-1 receptor are stabilized by ligands. The Journal of Biological Chemistry 289 20333-20344. (https://doi.org/10.1074/ jbc.M113.537993)

Hanner M, Moebius FF, Flandorfer A, Knaus HG, Striessnig J, Kempner E \& Glossmann H 1996 Purification, molecular cloning, and expression of the mammalian sigma1-binding site. Proceedings of the National Academy of Sciences of the United States of America 93 8072-8077. (https://doi.org/10.1073/pnas.93.15.8072)

Hasbi A, Fan T, Alijaniaram M, Nguyen T, Perreault ML, O’Dowd BF \& George SR 2009 Calcium signaling cascade links dopamine D1-D2 receptor heteromer to striatal BDNF production and neuronal growth. Proceedings of the National Academy of Sciences of the United States of America 106 21377-21382. (https://doi.org/10.1073/pnas.0903676106)

Hayashi T \& Su TP 2007 Sigma-1 receptor chaperones at the ERmitochondrion interface regulate $\mathrm{Ca} 2+$ signaling and cell survival. Cell 131 596-610. (https://doi.org/10.1016/j.cell.2007.08.036)

Hillion J, Canals M, Torvinen M, Casado V, Scott R, Terasmaa A, Hansson A, Watson S, Olah ME, Mallol J, et al. 2002 Coaggregation, cointernalization, and codesensitization of adenosine $\mathrm{A} 2 \mathrm{a}$ receptors and dopamine D2 receptors. The Journal of Biological Chemistry 277 18091-18097. (https://doi.org/10.1074/jbc.M107731200)

Kalivas PW 1993 Time course of extracellular dopamine to cocaine. II. Dopamine perikarya and behavioral sensitization. Brain Research $\mathbf{7 3}$ 276-284.

Kalivas PW \& Duffy P 1993 Time course of extracellular dopamine and behavioral sensitization to cocaine. I. Dopamine axon terminals. Journal of Neuroscience 13 266-275. (https://doi.org/10.1523/ JNEUROSCI.13-01-00266.1993)

Katz JL, Hiranita T, Hong WC, Job MO \& McCurdy CR 2017 A role for sigma receptors in stimulant self-administration and addiction. Handbook of Experimental Pharmacology 244 177-218. (https://doi. org/10.1007/164_2016_94)

Kim FJ, Kovalyshyn I, Burgman M, Neilan C, Chien CC \& Pasternak GW 2010 Sigma 1 Receptor modulation of G-protein-coupled receptor signaling: potentiation of opioid transduction independent from receptor binding. Molecular Pharmacology 77 695-703. (https://doi. org/10.1124/mol.109.057083)

Kourrich S, Hayashi T, Chuang JY, Tsai SY, Su TP \& Bonci A 2013 Dynamic interaction between sigma-1 receptor and Kv1.2 shapes neuronal and behavioral responses to cocaine. Cell 152 236-247. (https://doi.org/10.1016/j.cell.2012.12.004)
Kruse A 2017 Structural insights into sigma1 function. Handbook of Experimental Pharmacology 244 13-25. (https://doi. org/10.1007/164_2016_95)

Kukkonen JP \& Leonard CS 2014 Orexin/hypocretin receptor signalling cascades. British Journal of Pharmacology 171 314-331. (https://doi. org/10.1111/bph.12324)

Lee SP, So CH, Rashid AJ, Varghese G, Cheng R, Lança AJ, O'Dowd BF \& George SR 2004 Dopamine D1 and D2 receptor co-activation generates a novel phospholipase C-mediated calcium signal. The Journal of Biological Chemistry 279 35671-35678. (https://doi. org/10.1074/jbc.M401923200)

Leonard CS \& Kukkonen JP 2014 Orexin/hypocretin receptor signalling: a functional perspective. British Journal of Pharmacology 171 294-313. (https://doi.org/10.1111/bph.12296)

Lever JR, Fergason-Cantrell EA, Watkinson LD, Carmack TL, Lord SA, $\mathrm{Xu}$ R, Miller DK \& Lever SZ 2016 Cocaine occupancy of sigma 1 receptors and dopamine transporters in mice. Synapse 70 98-111. (https://doi.org/10.1002/syn.21877)

Lever JR, Miller DK, Green CL, Fergason-cantrell EA, Watkinson LD, Carmack TL, Fan KH \& Lever SZ 20142014 A selective sigma-2 receptor ligand antagonizes cocaine-induced hyperlocomotion in mice. Synapse 68 73-84. (https://doi.org/10.1002/syn.21717)

Marcellino D, Navarro G, Sahlholm K, Nilsson J, Agnati LF, Canela EI, Lluís C, Århem P, Franco R \& Fuxe K 2010 Cocaine produces D2Rmediated conformational changes in the adenosine $\mathrm{A}(2 \mathrm{~A})$ R-dopamine D2R heteromer. Biochemical and Biophysical Research Communications 394 988-992. (https://doi.org/10.1016/j. bbrc.2010.03.104)

Martin WR, Eades CG, Thompson JA, Huppler RE \& Gilbert PE 1976 The effects of morphine- and nalorphine- like drugs in the nondependent and morphine-dependent chronic spinal dog. The Journal of Pharmacology and Experimental Therapeutics 197 517-532.

Mary S, Fehrentz JA, Damian M, Gaibelet G, Orcel H, Verdié P, Mouillac B, Martinez J, Marie J \& Banères JL 2013 Heterodimerization with its splice variant blocks the ghrelin receptor 1a in a non-signaling conformation: a study with a purified heterodimer assembled into lipid discs. The Journal of Biological Chemistry 288 24656-24665. (https://doi.org/10.1074/jbc. M113.453423)

Matsumoto RR, Gilmore DL, Pouw B, Bowen WD, Williams W, Kausar A $\&$ Coop A 2004 Novel analogs of the $\sigma$ receptor ligand BD1008 attenuate cocaine-induced toxicity in mice. European Journal of Pharmacology 492 21-26. (https://doi.org/10.1016/j. ejphar.2004.03.037)

Matsumoto RR, Hewett KL, Pouw B, Bowen WD, Husbands SM, Cao JJ \& Newman AH 2001a Rimcazole analogs attenuate the convulsive effects of cocaine: correlation with binding to sigma receptors rather than dopamine transporters. Neuropharmacology 41 878-886. (https://doi.org/10.1016/s0028-3908(01)00116-2)

Matsumoto RR, McCracken KA, Pouw B, Miller J, Bowen WD, Williams W \& De Costa BR $2001 b \mathrm{~N}$-alkyl substituted analogs of the $\sigma$ receptor ligand BD1008 and traditional $\sigma$ receptor ligands affect cocaine-induced convulsions and lethality in mice. European Journal of Pharmacology 411 261-273. (https://doi.org/10.1016/S00142999(00)00917-1)

Matsumoto RR, McCracken KA, Friedman MJ, Pouw B, De Costa BR \& Bowen WD 2001c Conformationally restricted analogs of BD1008 and an antisense oligodeoxynucleotide targeting $\sigma 1$ receptors produce anti-cocaine effects in mice. European Journal of Pharmacology 419 163-174. (https://doi.org/10.1016/S00142999(01)00968-2)

Matsumoto RR, Liu Y, Lerner M, Howard EW \& Brackett DJ $2003 \sigma$ receptors: potential medications development target for anti-cocaine agents. European Journal of Pharmacology 469 1-12. (https://doi. org/10.1016/S0014-2999(03)01723-0) 
Matsumoto RR, Pouw B, Mack AL, Daniels A \& Coop A 2007 Effects of UMB24 and (+/-)-SM 21, putative sigma2-preferring antagonists, on behavioral toxic and stimulant effects of cocaine in mice. Pharmacology, Biochemistry, and Behavior 86 86-91. (https://doi. org/10.1016/j.pbb.2006.12.011)

Maurice T \& Romieu P 2004 Involvement of the sigma1 receptor in the appetitive effects of cocaine. Pharmacopsychiatry 37 S198-S207. (https://doi.org/10.1055/s-2004-832678)

Mavlyutov TA, Epstein ML, Verbny YI, Huerta MS, Zaitoun I, ZiskindConhaim L \& Ruoho AE 2013 Lack of sigma-1 receptor exacerbates ALS progression in mice. Neuroscience 240 129-134. (https://doi. org/10.1016/j.neuroscience.2013.02.035)

McCracken KA, Bowen WD, De Costa BR \& Matsumoto RR 1999 Two novel $\sigma$ receptor ligands, BD1047 and LR172, attenuate cocaineinduced toxicity and locomotor activity. European Journal of Pharmacology 370 225-232. (https://doi.org/10.1016/S00142999(99)00113-2)

Mei J \& Pasternak GW 2002 Sigma1 receptor modulation of opioid analgesia in the mouse. The Journal of Pharmacology and Experimental Therapeutics 300 1070-1074. (https://doi.org/10.1124/ jpet.300.3.1070)

Menkel M, Terry P, Pontecorvo M, Katz JL \& Witkin JM 1991 Selective o ligands block stimulant effects of cocaine. European Journal of Pharmacology 201 251-252. (https://doi.org/10.1016/00142999(91)90355-T)

Moreno E, Moreno-Delgado D, Navarro G, Hoffmann HM, Fuentes S, Rosell-Vilar S, Gasperini P, Rodríguez-Ruiz M, Medrano M, Mallol J, et al. 2014 Cocaine disrupts histamine $\mathrm{H} 3$ receptor modulation of dopamine D1 receptor signaling: $\sigma 1-\mathrm{D} 1-\mathrm{H} 3$ receptor complexes as key targets for reducing cocaine's effects. Journal of Neuroscience $\mathbf{3 4}$ 3545-3558. (https://doi.org/10.1523/JNEUROSCI.4147-13.2014)

Navarro G, Aguinaga D, Angelats E, Medrano M, Moreno E, Mallol J, Cortés A, Canela EI, Casadó V, McCormick PJ, et al. 2016 A significant role of the truncated ghrelin receptor GHS-R1b in ghrelininduced signaling in neurons. Journal of Biological Chemistry 291 13048-13062. (https://doi.org/10.1074/jbc.M116.715144)

Navarro G, Cordomí A, Brugarolas M, Moreno E, Aguinaga D, PérezBenito L, Ferre S, Cortés A, Casadó V, Mallol J, et al. 2018 Crosscommunication between Gi and Gs in a G-protein-coupled receptor heterotetramer guided by a receptor C-terminal domain. BMC Biology 16 24. (https://doi.org/10.1186/s12915-018-0491-x)

Navarro G, Moreno E, Aymerich M, Marcellino D, McCormick PJ, Mallol J, Cortes A, Casado V, Canela EI, Ortiz J, et al. 2010 Direct involvement of -1 receptors in the dopamine D1 receptor-mediated effects of cocaine. Proceedings of the National Academy of Sciences of the United States of America 107 18676-18681. (https://doi. org/10.1073/pnas.1008911107)

Navarro G, Moreno E, Bonaventura J, Brugarolas M, Farré D, Aguinaga D, Mallol J, Cortés A, Casadó V, Lluís C, et al. 2013 Cocaine inhibits dopamine D2 receptor signaling via sigma-1-D2 receptor heteromers. PLOS ONE $\mathbf{8}$ e61245. (https://doi.org/10.1371/ journal.pone.0061245)

Navarro G, Quiroz C, Moreno-Delgado D, Sierakowiak A, McDowell K, Moreno E, Rea W, Cai NS, Aguinaga D, Howell LA, et al. 2015 Orexin-corticotropin-releasing factor receptor heteromers in the ventral tegmental area as targets for cocaine. Journal of Neuroscience 35 6639-6653. (https://doi.org/10.1523/JNEUROSCI.4364-14.2015)

Perreault ML, Hasbi A, Alijaniaram M, Fan T, Varghese G, Fletcher PJ, Seeman P, O'Dowd BF \& George SR 2010 The dopamine D1-D2 receptor heteromer localizes in dynorphin/ enkephalin neurons: increased high affinity state following amphetamine and in schizophrenia. The Journal of Biological Chemistry 285 36625-36634. (https://doi.org/10.1074/jbc. M110.159954)

Perreault ML, Hasbi A, Shen MYF, Fan T, Navarro G, Fletcher PJPJ, Franco R, Lanciego JLJL \& George SRSR 2016 Disruption of a dopamine receptor complex amplifies the actions of cocaine. European Neuropsychopharmacology 26 1366-1377. (https://doi. org/10.1016/j.euroneuro.2016.07.008)

Radwanska K, Caboche J \& Kaczmarek L 2005 Extracellular signalregulated kinases (ERKs) modulate cocaine-induced gene expression in the mouse amygdala. European Journal of Neuroscience 22 939-948. (https://doi.org/10.1111/j.1460-9568.2005.04286.x)

Rashid AJ, So CH, Kong MMC, Furtak T, El-Ghundi M, Cheng R, O'Dowd BF \& George SR 2007 D1-D2 dopamine receptor heterooligomers with unique pharmacology are coupled to rapid activation of Gq/11 in the striatum. Proceedings of the National Academy of Sciences of the United States of America 104 654-659. (https://doi.org/10.1073/pnas.0604049104)

Rico AJ, Dopeso-Reyes IG, Martínez-Pinilla E, Sucunza D, Pignataro D, Roda E, Marín-Ramos D, Labandeira-García JL, George SR, Franco R, et al. 2016 Neurochemical evidence supporting dopamine D1-D2 receptor heteromers in the striatum of the long-tailed macaque: changes following dopaminergic manipulation. Brain Structure and Function 222 1-18. (https://doi.org/10.1007/s00429016-1306-x)

Romieu P, Martin-Fardon R \& Maurice T 2000 Involvement of the sigma1 receptor in the cocaine-induced conditioned place preference. NeuroReport 11 2885-2888. (https://doi. org/10.1097/00001756-200009110-00011)

Romieu P, Phan VL, Martin-Fardon R \& Maurice T 2002 Involvement of the sigma1receptor in cocaine-induced conditioned place preference: possible dependence on dopamine uptake blockade. Neuropsychopharmacology 26 444-455. (https://doi.org/10.1016/ S0893-133X(01)00391-8)

Schellekens H, Dinan TG \& Cryan JF 2013a Taking two to tango: a role for ghrelin receptor heterodimerization in stress and reward. Frontiers in Neuroscience 7 148. (https://doi.org/10.3389/fnins.2013.00148)

Schellekens H, van Oeffelen WEPA, Dinan TG \& Cryan JF 2013b Promiscuous dimerization of the growth hormone secretagogue receptor (GHS-R1a) attenuates ghrelin-mediated signaling. The Journal of Biological Chemistry 288 181-191. (https://doi.org/10.1074/ jbc.M112.382473)

Schmidt HR, Zheng S, Gurpinar E, Koehl A, Manglik A \& Kruse AC 2016 Crystal structure of the human $\sigma 1$ receptor. Nature 532 527-530. (https://doi.org/10.1038/nature17391)

Schwarze SR, Ho A, Vocero-Akbani A \& Dowdy SF 1999 In vivo protein transduction: delivery of a biologically active protein into the mouse. Science 285 1569-1572. (https://doi.org/10.1126/ science.285.5433.1569)

Shull KR 2002 Contact mechanics and the adhesion of soft solids. Materials Science and Engineering: R: Reports 36 1-45. (https://doi org/10.1016/S0927-796X(01)00039-0)

Skuza G 1999 Effect of sigma ligands on the cocaine-induced convulsions in mice. Polish Journal of Pharmacology 51 477-483.

Su TP, Hayashi T, Maurice T, Buch S \& Ruoho AE 2010 The sigma-1 receptor chaperone as an inter-organelle signaling modulator. Trends in Pharmacological Sciences 31 557-566. (https://doi.org/10.1016/j. tips.2010.08.007)

Su TP, Su TC, Nakamura Y \& Tsai SY 2016 The sigma-1 receptor as a pluripotent modulator in living systems. Trends in Pharmacological Sciences 37 262-278. (https://doi.org/10.1016/j.tips.2016.01.003)

Sun H, Shi M, Zhang W, Zheng YM, Xu YZ, Shi JJ, Liu T, Gunosewoyo H, Pang T, Gao ZB, et al. 2016 Development of novel alkoxyisoxazoles as sigma-1 receptor antagonists with antinociceptive efficacy. Journal of Medicinal Chemistry 59 6329-6343. (https://doi.org/10.1021/acs.jmedchem.6b00571)

Uchimura N \& North RA 1990 Actions of cocaine on rat nucleus accumbens neurones in vitro. British Journal of Pharmacology $99736-$ 740. (https://doi.org/10.1111/j.1476-5381.1990.tb12999.x)

Ujike H, Kuroda S \& Otsuki S $1996 \sigma$ receptor antagonists block the development of sensitization to cocaine. European Journal of 
Pharmacology 296 123-128. (https://doi.org/10.1016/00142999(95)00693-1)

Valjent E, Corbille AG, Bertran-Gonzalez J, Herve D \& Girault JA 2006 Inhibition of ERK pathway or protein synthesis during reexposure to drugs of abuse erases previously learned place preference. Proceedings of the National Academy of Sciences of the United States of America 103 2932-2937. (https://doi.org/10.1073/pnas.0511030103)

Valjent E, Pagès C, Hervé D, Girault JA \& Caboche J 2004 Addictive and non-addictive drugs induce distinct and specific patterns of ERK activation in mouse brain. European Journal of Neuroscience 19 18261836. (https://doi.org/10.1111/j.1460-9568.2004.03278.x)

Vaupel DB 1983 Naltrexone fails to antagonize the sigma effects of PCP and SKF 10,047 in the dog. European Journal of Pharmacology 92269 274. (https://doi.org/10.1016/0014-2999(83)90297-2)

Witkin JM, Terry P, Menkel M, Hickey P, Pontecorvo M, Ferkany J \& Katz JL 1993 Effects of the selective sigma receptor ligand, 6-[6-(4-hydroxypiperidinyl)hexyloxy]-3-methylflavone (NPC 16377), on behavioral and toxic effects of cocaine. Journal of Pharmacology \& Experimental Therapeutics 266 473-482.

Wu Z \& Bowen WD 2008 Role of sigma-1 receptor C-terminal segment in inositol 1,4,5-trisphosphate receptor activation: constitutive enhancement of calcium signaling in MCF-7 tumor cells. The Journal of Biological Chemistry 283 28198-28215. (https://doi.org/10.1074/ jbc.M802099200)

Yano H, Bonifazi A, Xu M, Guthrie DA, Schneck SN, Abramyan AM, Fant AD, Hong WC, Newman AH \& Shi L 2018 Pharmacological profiling of sigma 1 receptor ligands by novel receptor homomer assays. Neuropharmacology 133 264-275. (https://doi.org/10.1016/j. neuropharm.2018.01.042)

Zhang LLL, Huang L, Lu K, Liu Y, Tu G, Zhu M, Ying L, Zhao J, Liu N, Guo F, et al. 2017 Cocaine-induced synaptic structural modification is differentially regulated by dopamine D1 and D3 receptorsmediated signaling pathways. Addiction Biology 22 1842-1855. (https://doi.org/10.1111/adb.12462)

Received in final form 10 September 2019

Accepted 19 September 2019

Accepted Preprint published online 19 September 2019
(C) 2019 Society for Endocrinology Published by Bioscientifica Ltd. Printed in Great Britain 